\title{
Dynamic in vitro intestinal barrier model coupled to chip-based liquid chromatography mass spectrometry for oral bioavailability studies
}

\author{
Milou J. C. Santbergen ${ }^{1,2} \cdot$ Meike van der Zande $^{3} \cdot$ Arjen Gerssen $^{3} \cdot$ Hans Bouwmeester $^{4} \cdot$ Michel W. F. Nielen $^{1,3}$
}

Received: 14 October 2019 /Revised: 19 November 2019 / Accepted: 6 December 2019 / Published online: 21 December 2019

(C) The Author(s) 2019

\begin{abstract}
In oral bioavailability studies, evaluation of the absorption and transport of drugs and food components across the intestinal barrier is crucial. Advances in the field of organ-on-a-chip technology have resulted in a dynamic gut-on-a-chip model that better mimics the in vivo microenvironment of the intestine. Despite a few recent integration attempts, ensuring a biologically relevant microenvironment while coupling with a fully online detection system still represents a major challenge. Herein, we designed an online technique to measure drug permeability and analyse unknown product formation across an intestinal epithelial layer of Caco-2 and HT29-MTX cells cultured on a flow-through Transwell system, while ensuring the quality and relevance of the biological model. Chip-based ultra-performance liquid chromatography quadrupole time-of-flight mass spectrometry (UPLCQTOF-MS) was coupled to the dynamic Transwell system via a series of switching valves, thus allowing alternating measurements of the apical and basolateral sides of the in vitro model. Two trap columns were integrated for online sample pre-treatment and compatibility enhancement. Temporal analysis of the intestinal permeability was successfully demonstrated using verapamil as a model drug and ergotamine epimers as a model for natural toxins present in foods. Evidence was obtained that our newly developed dynamic system provided reliable results versus classical static in vitro models, and moreover, for the first time, epimer-specific transport is shown for ergotamine. Finally, initial experiments with the drug granisetron suggest that metabolic activity can be studied as well, thus highlighting the versatility of the bio-integrated online analysis system developed.
\end{abstract}

Keywords Gut-on-a-chip · Chip-based liquid chromatography $\cdot$ Mass spectrometry $\cdot$ Intestinal barrier $\cdot$ Oral bioavailability

\section{Introduction}

To predict the in vivo bioavailability of drugs and dietary compounds, currently static in vitro cell culture models of

Electronic supplementary material The online version of this article (https://doi.org/10.1007/s00216-019-02336-6) contains supplementary material, which is available to authorized users.

Michel W. F. Nielen

michel.nielen@wur.nl

1 Laboratory of Organic Chemistry, Wageningen University, Stippeneng 4, 6708 WE Wageningen, The Netherlands

2 TI-COAST, Science Park 904, 1098 XH Amsterdam, The Netherlands

3 Wageningen Food Safety Research (WFSR), Wageningen University \& Research, P.O. Box 230, 6700 AE Wageningen, The Netherlands

4 Division of Toxicology, Wageningen University, Stippeneng 4, 6708 WE Wageningen, The Netherlands the intestinal barrier are used. Often in these in vitro models, differentiated Caco-2 and HT29-MTX cells are used to model the intestinal epithelium [1]. Caco-2 cells are human intestinal epithelial cells which are able to form a tight polarized monolayer [2]. HT29-MTX cells are human mucin-producing goblet cells, depositing mucin on top of the cell barrier [3]. The incorporation of a mucin layer on the monolayer of cells renders an in vitro model that better mimics the in vivo intestinal barrier properties than a single Caco- 2 cell model. These cells are generally cultured in a so-called Transwell system (Fig. 1a), which is a well-known system for permeability studies $[4,5]$. Transwell systems are inserts containing a porous membrane on which monolayers of cells can be grown, creating an apical (lumen) and basolateral (bloodstream) compartment. A compound of interest is applied apically and allowed to permeate through the intestinal cell layer. Periodically, samples are taken from the apical and basolateral sides for measurement, to calculate the permeability of the compound. However, such a Transwell system has its limitations as the 
a

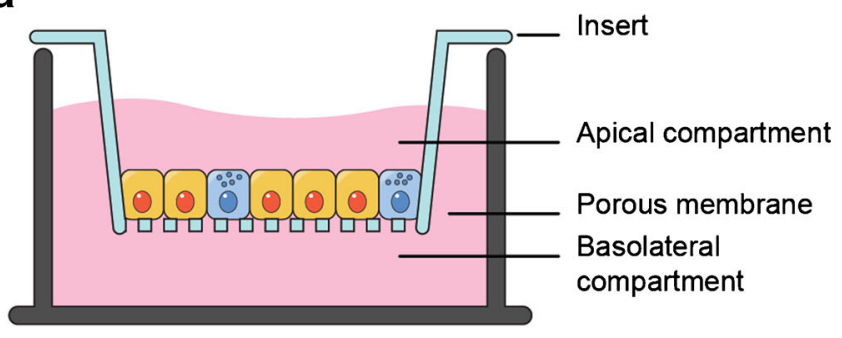

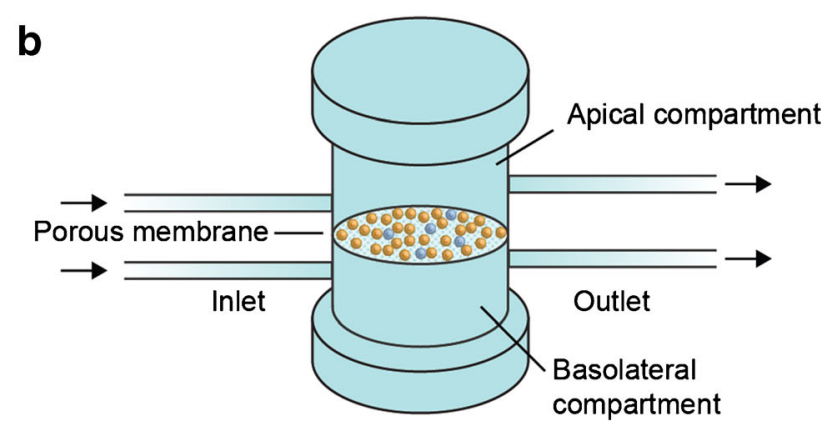

Fig. 1 Schematic representation of (a) traditional Transwell insert and (b) dynamic flow-through Transwell system

cells are grown in a static environment, thus ignoring the dynamic nature of the intestine.

Recent advances in organ-on-a-chip technology have led to state-of-the-art in vitro cell culture systems that include mechanical and functional features present in the human body, resulting in a much better representation of the in vivo microenvironment [6-8]. The gut-on-a-chip is an in vitro cell culture system that resembles the dynamic environment of the intestine. Several different geometries and designs have been developed for gut-on-a-chip devices, but two main types of designs are commonly found in the literature. The first one is based on the traditional Transwell system, where intestinal cells are grown on a circular porous membrane [9-12], and the second one is based on culturing cells on a porous membrane that separates two sides of a linear channel or tube [13-17]. Both types of systems contain an apical and basolateral flow of cell culture medium inducing shear forces on the cells and mimicking the luminal flow and blood flow. Dynamic flow systems not only feature a much better representation of the in vivo environment but also can reduce the use of cell culture media and bioreagents. Lastly, dynamic flow systems provide the possibility to fully automate the system by integration with an analytical detection system [18]. The latter, however, implies challenges for measurements, as the cell culture medium has a complex chemical composition that typically contains very high concentrations of salts, proteins, dyes and antibiotic drugs, which is not compatible with most analytical equipment.

Theoretically, electrospray ionization mass spectrometry (ESI-MS) would be the technique of choice for integration with a gut-on-a-chip device, as ionization takes place in the liquid phase. Furthermore, MS is well suited for multi-analyte detection, and apart from analyte transport across the cellular barrier, also unknown product formation (e.g. metabolites) can be monitored. However, due to the complex chemical composition of the cell culture medium, integration of dynamic in vitro models with ESI-MS requires extensive sample preparation in order to ensure system compatibility. Several semi-integrated systems have been reported, in which solidphase extraction (SPE) columns were used as a sample pre- treatment step [19-23]. In these reports, the sample pretreatment steps required manual operations to flush the SPE column, hampering full automation and compromising robustness of the system. Few online integrations have been described in the literature $[24,25]$, but unfortunately, they did not report on biological integrity for assuring a relevant organ-on-a-chip model. A complete online integration featuring an evidence-based biologically relevant dynamic in vitro model of the intestine and ESI-MS detection system has not been described yet in the literature.

In this study, we uniquely integrated a dynamic in vitro model of the intestine with a chip-based ultra-performance liquid chromatography quadrupole time-of-flight (UPLCQTOF) MS analysis system for oral bioavailability and biotransformation studies. This combines a dynamic cell barrier system together with automated and continuous analytical readout of translocation processes and cell-induced product formation while maintaining full biological integrity and without compromising the analytical performance. For this, a coculture of Caco-2 and HT29-MTX cells was grown in a flowthrough Transwell system (Fig. 1b) and connected to the UPLC-QTOF-MS via a series of switching valves. The switching valves allowed for alternating UPLC-QTOF-MS measurements of the apical and basolateral sides of the flowthrough Transwell system. Prior to chromatographic separation, two trapping columns were integrated in the series of switching valves for sample pre-treatment. To benchmark the online total analysis system for absorption studies, the permeability of two model compounds was examined (i.e. verapamil and ergotamine), in three different set-ups following a tiered approach. Firstly, permeability was evaluated in the traditional static Transwell system which allowed benchmarking against in vitro permeability data found in the literature. Secondly, permeability was evaluated in the flowthrough Transwell system with offline measurements resulting in a one-to-one comparison between static and dynamic model systems. Thirdly, a truly automated online system was developed and compared to the offline flow-through Transwell version in order to assess the potential impact of its intrinsically higher complexity. Lastly, some initial experiments have been 
performed with the drug granisetron in order to show future application of the online analysis system for biotransformation studies.

\section{Experimental section}

\section{Chemicals and reagents}

Verapamil hydrochloride, ergotamin(in)e D-tartrate, penicillin-streptomycin, formic acid, Lucifer yellow, 4-(2hydroxyethyl)-1-piperazineethanesulfonic acid (HEPES), sodium bicarbonate $\left(\mathrm{NaHCO}_{3}\right)$, ammonium carbonate, Triton X-100 and Hank's balanced salt solution (HBSS), with and without phenol red, were purchased from Sigma-Aldrich/ Merck (Zwijndrecht, The Netherlands). Dulbecco's Modified Eagle Medium (DMEM) with $4.5 \mathrm{~g} / \mathrm{L}$ glucose and L-glutamine with and without phenol red, bovine serum albumin (BSA) and heat-inactivated foetal bovine serum (FBS) were purchased from Gibco (Bleiswijk, The Netherlands). Rabbit polyclonal antibody ZO-1/TJP1-Alexa Fluor 594, 4',6-diamidino-2-phenylindole (DAPI), ProLong Diamond Antifade Mountant, dimethyl sulfoxide (DMSO), phosphatebuffered saline (PBS) and non-essential amino acids (NEAA) were obtained from Thermo Fisher Scientific (Landsmeer, The Netherlands). Acetonitrile and methanol were purchased from Actu-All Chemicals (Oss, The Netherlands). UPLC-MS grade water was purchased from Biosolve (Valkenswaard, The Netherlands). Granisetron was purchased from TCI Europe (Zwijndrecht, Belgium), paraformaldehyde from VWR (Amsterdam, The Netherlands) and water-soluble tetrazolium salt (WST-1) reagent from Roche Diagnostics $\mathrm{GmbH}$ (Mannheim, Germany), and water was prepared daily using a Milli-Q Reference Water Purification System from Millipore (Burlington, MA, USA).

\section{Cell culturing}

The human colonic adenocarcinoma Caco-2 cell line was obtained from the American Type Culture Collection (ATCC, Manassas, VA, USA), and the human colon adenocarcinoma mucus-secreting HT29-MTX-E12 cell line was obtained from the European Collection of Authenticated Cell Cultures (ECACC, Salisbury, UK). Caco-2 cells were used at passage numbers 29-40, and HT29-MTX-E12 cells were used at passage numbers 52-70 for all experiments. Cells were cultured in DMEM containing $10 \%$ FBS, $1 \%$ NEAA and $1 \%$ penicillin-streptomycin and maintained at $37{ }^{\circ} \mathrm{C}$ in a $5 \%$ $\mathrm{CO}_{2}$-humidified air atmosphere and subcultured every 2 days to 3 days similar to the study of Abdelkhaliq et al. [26]. For permeability experiments, cells were seeded at a density of $40,000 \mathrm{cells} / \mathrm{cm}^{2}$ on a polycarbonate Transwell insert (area $0.6 \mathrm{~cm}^{2}, 0.4 \mu \mathrm{m}$ pore size; Millipore) as follows: Caco-2 and HT29-MTX-E12 cells were seeded in a 3:1 ratio on the apical side of the Transwell system and allowed to attach for $24 \mathrm{~h}$. After $24 \mathrm{~h}$, cell culture medium was refreshed every 2 3 days and Transwell systems were used for permeability experiments following 21 days of culturing.

\section{Evaluation of cell viability}

Possible cytotoxic effects of verapamil, ergotamin(in)e and granisetron were evaluated using the cell proliferation WST1 assay. With the WST-1 assay, mitochondrial activity of the cell is measured by the conversion of WST-1 into formazan dye by mitochondrial dehydrogenase enzymes. The assay is performed as follows: Caco-2 and HT29-MTX-E12 cells (ratio 3:1) were seeded in Greiner Bio-One (Alphen aan den Rijn, The Netherlands) flat-bottom 96-well plates at a concentration of $1 \times 10^{5}$ cells $/ \mathrm{mL}$ in cell culture medium $(100 \mu \mathrm{L} /$ well). Plates were incubated for $24 \mathrm{~h}$ at $37{ }^{\circ} \mathrm{C}$ under $5 \% \mathrm{CO}_{2}$. Cell culture medium was removed, and subsequently, the cells were exposed to $100 \mu \mathrm{L} /$ well serial dilutions of verapamil ( 0 $500 \mu \mathrm{g} / \mathrm{mL})$, ergotamin(in)e $(0-20 \mu \mathrm{g} / \mathrm{mL})$ or granisetron $(0$ $1000 \mu \mathrm{g} / \mathrm{mL}$ ) in cell culture medium for $24 \mathrm{~h}$, at $37^{\circ} \mathrm{C}$. Then, the exposure medium containing (dilutions of) the compounds of interest was discarded and the cells were washed with prewarmed HBSS. Subsequently, WST-1 reagent (in cell culture medium without phenol red) was added to the cells $(1: 10$, $100 \mu \mathrm{L} /$ well). After $1.5 \mathrm{~h}$ of incubation at $37^{\circ} \mathrm{C}$, the absorbance of each well was measured at $440 \mathrm{~nm}$ using a Bio-Tek (Winooski, VT, USA) Synergy HT Multi-Mode microplate reader. The viability of the cells for each concentration of verapamil and granisetron was expressed as a percentage of the negative control consisting of only cell culture medium. In the case of ergotamin(in)e, cell culture medium with $0.5 \%$ DMSO was used as a negative control, as ergotamin(in)e was dissolved in cell culture medium using $0.5 \%$ DMSO. Triton X-100 $(0.25 \%, \mathrm{v} / \mathrm{v})$ was used as a positive control in all cell viability assays and decreased the cell viability to $0.4 \% \pm 0.3 \%$.

\section{Evaluation of cell barrier integrity}

Barrier integrity was evaluated similar to the study of Hubatsch et al. [27], and cells were cultured on a Transwell membrane for 21 days and subsequently stained for tight junction protein ZO-1 and the cell nuclei. For this, the cells were washed with PBS and fixed with $4 \%$ paraformaldehyde $(\mathrm{w} / \mathrm{v})$ for $15 \mathrm{~min}$. Cells were permeabilized with $0.25 \%$ Triton X$100(\mathrm{v} / \mathrm{v})$ and blocked with $1 \%$ BSA (w/v). The cells were then incubated with the conjugated antibody ZO-1/TJP1Alexa Fluor 594 for $45 \mathrm{~min}(10 \mu \mathrm{g} / \mathrm{mL})$. Subsequently, DAPI was used to stain the nuclei for $10 \mathrm{~min}(5 \mu \mathrm{g} / \mathrm{mL})$. Between incubations, cells were washed with PBS three times. Cells were mounted in a $120-\mu \mathrm{m}$ spacer (Sigma- 
Aldrich) on a microscope slide (Thermo Scientific) with ProLong Diamond Antifade Mountant. Slides were then examined using a Zeiss (Jena, Germany) LSM 510 META confocal microscope. Samples were excited with $405-\mathrm{nm}$ and $543-\mathrm{nm}$ lasers, and the pinholes were in the range of 90 $94 \mu \mathrm{m}$ at a magnification of $\times 40$. Cell layer integrity was also evaluated using the transport marker Lucifer yellow. Following permeability experiments, the cells were incubated with Lucifer yellow at a concentration of $500 \mu \mathrm{g} / \mathrm{mL}$ for 30 min on the apical side of the Transwell insert. Cell culture medium was collected from the apical and basolateral sides at $t=0$ and $t=30 \mathrm{~min}$ and analysed for fluorescence at $458 \mathrm{~nm} /$ $530 \mathrm{~nm}$ using a Bio-Tek Synergy HT Multi-Mode microplate reader. Cell layers that transported more than $5 \%$ of Lucifer yellow to the basolateral compartment were judged as leaking and were discarded.

\section{Cell permeability experiments using static and dynamic offline Transwell systems}

For the static and dynamic offline cell permeability experiments, verapamil $(5 \mu \mathrm{g} / \mathrm{mL})$ and ergotamin(in)e $(10 \mu \mathrm{g} / \mathrm{mL}$ ) were used suspended in HBSS (without phenol red) containing $25 \mathrm{mM}$ of HEPES and $0.35 \mathrm{~g} / \mathrm{L}$ $\mathrm{NaHCO}_{3}$ as the donor solution. HEPES is added because the experiments with the flow-through Transwell systems are performed outside of a $\mathrm{CO}_{2}$-controlled incubator, and for the sake of comparability, it is added to the static Transwell systems as well. For the static Transwell experiments, these donor solutions were directly applied apically onto the cells ( $400 \mu \mathrm{L} /$ insert), at day 21 of culturing. The basolateral side of the insert was filled with the same solution $(600 \mu \mathrm{L} /$ insert $)$, but without the compound of interest (receiving solution). Samples $(100 \mu \mathrm{L})$ were collected and replenished on the basolateral side at the following time points: $15 \mathrm{~min}, 30 \mathrm{~min}, 45 \mathrm{~min}$, $60 \mathrm{~min}, 120 \mathrm{~min}$ and $180 \mathrm{~min}$. Apical samples were taken at $t=0 \mathrm{~min}$ and $t=180 \mathrm{~min}$. For the dynamic experiments, the Transwell inserts were placed into the QV600 system from Kirkstall (Rotherham, UK), further referred to as a flow-through Transwell system (see also Fig. 1b), at day 20 of culture. Cell culture medium containing $25 \mathrm{mM}$ HEPES was perfused into the apical compartment $(200 \mu \mathrm{L} / \mathrm{min})$ and basolateral compartment (100 $\mathrm{\mu L} / \mathrm{min})$ of the flow-through Transwell system using a New Era Pump Systems (Farmingdale, NY, USA) syringe pump for $24 \mathrm{~h}$ at $37{ }^{\circ} \mathrm{C}$, as described by Giusti et al. [28]. After $24 \mathrm{~h}$, the apical syringe was replaced by a syringe containing the donor solution and the basolateral syringe was replaced by a syringe containing the receiving solution. In order to assure a biologically relevant environment, syringe heaters (New Era Pump Systems) were used to heat the medium and keep the cells at $37{ }^{\circ} \mathrm{C}$ without the need for an additional incubator. Both effluent flows were attached to a Gilson 234 autosampler (Villiers-le-Bel, France) which was used as a fraction collector, collecting samples every $2 \mathrm{~min}$ in 96-well plates. All experiments were conducted in biological triplicates.

\section{Offline targeted LC-MS/MS analysis}

\section{Verapamil}

Verapamil static and dynamic offline Transwell samples were diluted 500 times in water prior to LC-MS/MS analysis. Chromatographic separation was achieved using a Waters (Milford, MA, USA) Acquity I Class UPLC system equipped with an Acquity UPLC BEH C18 $(100 \mathrm{~mm} \times 2.1 \mathrm{~mm}$, $1.7 \mu \mathrm{m}$ ) column (Waters). The column temperature was kept at $50{ }^{\circ} \mathrm{C}$, and the autosampler was set at $10{ }^{\circ} \mathrm{C}$. A $2.5 \mu \mathrm{L}$ injection volume was used. Mobile phase A was water, and mobile phase $\mathrm{B}$ was acetonitrile, both containing $5 \mathrm{mM}$ formic acid. The mobile phase gradient started at $10 \% \mathrm{~B}$ and, after $0.8 \mathrm{~min}$, was linearly increased to $40 \% \mathrm{~B}$ in 2 min followed by an increase to $99 \%$ B in $0.1 \mathrm{~min}$. This composition was kept for $3 \mathrm{~min}$ and returned to $10 \% \mathrm{~B}$ in $0.1 \mathrm{~min}$, all at a constant flow rate of $0.6 \mathrm{~mL} / \mathrm{min}$. A mobile phase equilibration time of $1.1 \mathrm{~min}$ was allowed prior to the next injection. The first minute of the gradient elution was directed to waste in order to prevent any salts from the HBSS matrix to enter the ionization source. Mass spectrometric detection was performed using a Waters Xevo TQS tandem mass spectrometer equipped with an electrospray ionization interface (ESI) and operated in positive ion mode, with a capillary voltage of $3.1 \mathrm{kV}$, a desolvation temperature of $450^{\circ} \mathrm{C}$, a gas flow rate of $800 \mathrm{~L} / \mathrm{h}$, a source temperature of $150{ }^{\circ} \mathrm{C}$ and a cone gas flow rate of $150 \mathrm{~L} / \mathrm{h}$. For verapamil, three multiple reaction monitoring (MRM) transitions were acquired (Table S1 in the Electronic Supplementary Material, ESM). For quantification of verapamil, a calibration curve was constructed. Calibration solutions were prepared in HBSS and subsequently diluted in water similar as the samples, resulting in a calibration curve with the following points: $0 \mu \mathrm{g} / \mathrm{mL}, 0.01 \mu \mathrm{g} / \mathrm{mL}, 0.05 \mu \mathrm{g} / \mathrm{mL}$, $0.1 \mu \mathrm{g} / \mathrm{mL}, 0.25 \mu \mathrm{g} / \mathrm{mL}, 0.5 \mu \mathrm{g} / \mathrm{mL}, 1 \mu \mathrm{g} / \mathrm{mL}$ and $5 \mu \mathrm{g} / \mathrm{mL}$. Limit of detection (LOD) and limit of quantification (LOQ) were calculated as the average signal of five blank samples plus three (LOD) or ten (LOQ) times the standard deviation (SD) of the blank samples divided by the sensitivity (slope of the calibration curve) using the transition $\mathrm{m} / \mathrm{z} 455.4>165.1$, resulting in a LOD of $3.3 \mathrm{ng} / \mathrm{mL}$ and a LOQ of $9.6 \mathrm{ng} / \mathrm{mL}$. The concentration of verapamil in the unknown samples was then calculated using peak area measurements in the reconstructed ion current (RIC) of the respective MRM transitions via interpolation of the external matrix-matched calibration curve $\left(r^{2}=0.99\right)$. 


\section{Ergotamin(in)e}

Apical and basolateral ergotamin(in)e samples of the static Transwell experiments were diluted 20 times in methanol/ water $60: 40(\mathrm{v} / \mathrm{v})$ ratio prior to LC-MS/MS analysis, as were the apical Transwell samples of the dynamic experiments. The basolateral samples of the dynamic experiments were analysed undiluted. LC-MS/MS analysis was performed as described for verapamil with the following modifications: a $2 \mu \mathrm{L}$ injection volume was used. Mobile phase A consisted of $10 \mathrm{mM}$ ammonium carbonate in water ( $\mathrm{pH} 9)$, and mobile phase B consisted of acetonitrile. The mobile phase gradient started at $0 \% \mathrm{~B}$ and was linearly increased to $10 \% \mathrm{~B}$ in $1 \mathrm{~min}$ followed by an increase to $30 \% \mathrm{~B}$ in $10 \mathrm{~min}$ and returned to $0 \% \mathrm{~B}$ in $0.2 \mathrm{~min}$, all at a constant flow rate of $0.4 \mathrm{~mL} / \mathrm{min}$. A mobile phase equilibration time of 2.6 min was allowed prior to the next injection. The first minute of the gradient elution was directed to waste to prevent salts from the HBSS matrix to enter the ion source of the MS. Mass spectrometric detection was performed as described for verapamil with the following modifications: the mass spectrometer was operated in positive ion mode with a capillary voltage of $3.0 \mathrm{kV}$ and a desolvation temperature of $600{ }^{\circ} \mathrm{C}$. For ergotamin(in)e, four MRM transitions were measured (ESM Table S1). For quantification of ergotamin(in)e, a calibration curve was constructed. Calibration solutions were prepared in HBSS and subsequently diluted in methanol/water 60:40 $(\mathrm{v} / \mathrm{v})$ ratio similar as the samples, resulting in a calibration curve with the following points: $0 \mu \mathrm{g} / \mathrm{mL}, 0.01 \mu \mathrm{g} / \mathrm{mL}$, $0.05 \mu \mathrm{g} / \mathrm{mL}, 0.1 \mu \mathrm{g} / \mathrm{mL}, 0.5 \mu \mathrm{g} / \mathrm{mL}, 1 \mu \mathrm{g} / \mathrm{mL}, 2.5 \mu \mathrm{g} /$ $\mathrm{mL}, 5 \mu \mathrm{g} / \mathrm{mL}$ and $10 \mu \mathrm{g} / \mathrm{mL}$. LOD and LOQ were calculated as the average signal of five blank samples plus three (LOD) or ten (LOQ) times the SD of the blank samples divided by the sensitivity (slope of the calibration curve) using the transition $\mathrm{m} / \mathrm{z} 582.4>208.1$, resulting in a LOD of $1 \mathrm{ng} / \mathrm{mL}$ and a LOQ of $1.9 \mathrm{ng} / \mathrm{mL}$. The concentration of ergotamin(in)e in the unknown samples was then calculated using the peak area measurements in the RIC of the respective MRM transitions via interpolation of the external matrix-matched calibration curve $\left(r^{2}=0.99\right)$.

\section{Flow-through Transwell system coupled online with chip-based UPLC-QTOF-MS}

All dynamic online cellular experiments were conducted using the flow-through Transwell system (Fig. 1b). A series of three 2-position/10-port UltraLife switching valves (IDEX Health \& Science, Oak Harbor, WA, USA) with 1/16" fittings were used to interface the flow-through Transwell system to the chip-based UPLC-QTOF-MS. Apical and basolateral effluents from the flow-through Transwell system were alternatingly loaded onto $5-\mu \mathrm{L}$ stainless steel sample loops, mounted on the first and second switching valves (Fig. 2). Each sample loop was loaded for $15 \mathrm{~min}$ at $200 \mu \mathrm{L} / \mathrm{min}$ (apical) and $100 \mu \mathrm{L} / \mathrm{min}$ (basolateral), and the detailed valve switching program is listed in Table S2 (ESM). After $15 \mathrm{~min}$ of sample collection, the sample loop was flushed for $4 \mathrm{~min}$ towards an Optimize Technologies (Oregon City, OR, USA) C8 trapping column $(180 \mu \mathrm{m} \times 5 \mathrm{~mm}, 2.7 \mu \mathrm{m})$ using an aqueous solvent $\left(\mathrm{H}_{2} \mathrm{O}\right.$ with $1 \%$ acetonitrile $)$ at a flow rate of $20 \mu \mathrm{L} /$ min. Following the clean-up, the trap column was eluted towards an iKey Chip BEH C18 analytical column $(150 \mu \mathrm{m} \times$ $50 \mathrm{~mm}, 1.7 \mu \mathrm{m}$ ) (Waters). The $3 \mu \mathrm{L} / \mathrm{min}$ microflow gradient for verapamil and granisetron experiments consisted of mobile phase A (water with $1 \%$ acetonitrile) and mobile phase $\mathrm{B}$ (acetonitrile with 1\% water), both containing $0.1 \%$ formic acid. The gradient started at $0 \% \mathrm{~B}$ and, after $4 \mathrm{~min}$, was linearly increased to $100 \% \mathrm{~B}$ in $4 \mathrm{~min}$. This composition was kept for $3 \mathrm{~min}$ and returned to $0 \% \mathrm{~B}$ in $0.1 \mathrm{~min}$. An equilibration time of $3.9 \mathrm{~min}$ was allowed prior to the next injection. For ergotamin(in)e experiments, the gradient consisted of mobile phase $\mathrm{A}$ (water with $10 \mathrm{mM}$ ammonium carbonate) ( $\mathrm{pH}$ 9) and mobile phase B (acetonitrile). The gradient started at $30 \% \mathrm{~B}$ and, after $4 \mathrm{~min}$, was linearly increased to $70 \% \mathrm{~B}$ in $6 \mathrm{~min}$. This composition was kept for $1 \mathrm{~min}$ and returned to $30 \% \mathrm{~B}$ in $0.2 \mathrm{~min}$. An equilibration time of $3.8 \mathrm{~min}$ was allowed prior to the next injection. The complete process is illustrated in Fig. 2. Data were collected using MassLynx v4.1 software, yielding a separate data file for each trap column analysis or, in other words, alternatingly, for the apical and basolateral sides of the dynamic in vitro model. For quantification, the peak area of the RIC of the basolateral measurement was relative to the average peak area of the RIC in the apical sample measurements. Mass spectrometric detection was performed with a Waters ionKey Xevo QTOF MS system. The mass spectrometer was operated in positive ion mode, with a capillary voltage of $3.9 \mathrm{kV}$, a desolvation temperature of $350^{\circ} \mathrm{C}$, a gas flow rate of $400 \mathrm{~L} / \mathrm{h}$, a source temperature of $80^{\circ} \mathrm{C}$ and a cone gas flow rate of $10 \mathrm{~L} / \mathrm{h}$.

\section{Permeability calculations}

The apparent permeability coefficient $\left(P_{\mathrm{app}}, \mathrm{cm} / \mathrm{s}\right)$ was calculated as described by Yeon and Park [29], according to the following equation:

$P_{\mathrm{app}}=\frac{\mathrm{d} Q}{\mathrm{~d} t} \frac{1}{A C_{0}}$

where $\mathrm{d} Q / \mathrm{d} t$ is the cumulative transport rate in the basolateral compartment ( $\mu \mathrm{mol} / \mathrm{s}), A$ is the surface area of the cell layer $\left(0.6 \mathrm{~cm}^{2}\right)$ and $C_{0}$ is the initial concentration of the compounds in the apical compartment $\left(\mu \mathrm{mol} / \mathrm{cm}^{3}\right)$. 

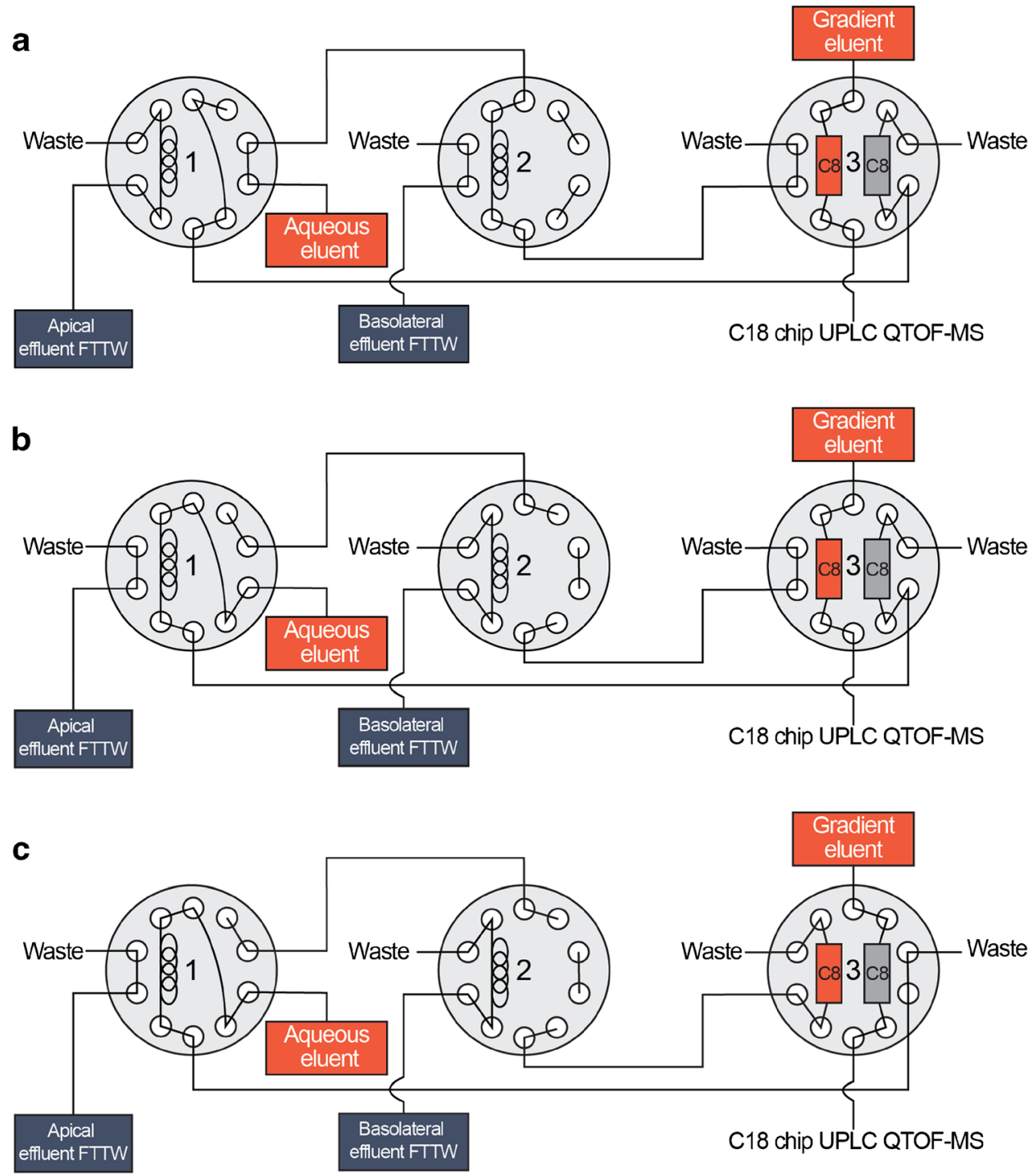

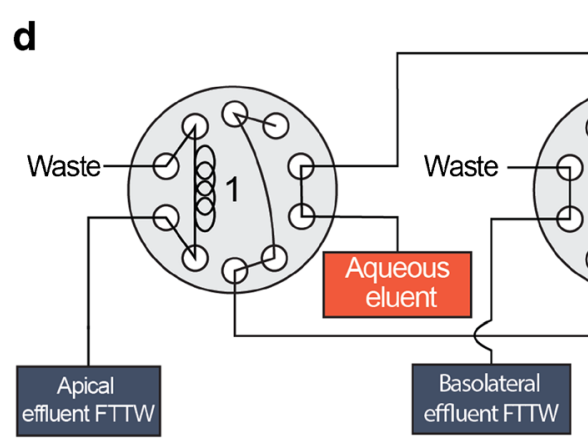

Fig. 2 Schematic representation of the flow-through Transwell (FTTW) system coupled to chip-based UPLC-QTOF-MS using parallel traps as interface. The set-up consists of three switching valves, two sample loops, two C8 trap columns and a C18 chip analytical column. (a) Sample effluent from the apical side of the FTTW system fills the sample loop in the first switching valve for $15 \mathrm{~min}$, while an aqueous effluent flows through the second sample loop to the waste. (b) After the 15-min sample collection, the first valve switches and aqueous effluent flows through the first sample loop towards the C8 trap column in the third switching valve. The aqueous effluent loads the sample onto the trap column and rinses away the salts. At the same time, the second valve switches to collect effluent from the basolateral side of the FTTW system. (c) Subsequently, a gradient from aqueous to organic solvent runs through the trap column in the third valve, through the analytical column and to the MS. (d) The next valve switch flushes the sample collected from the basolateral side of the FTTW system to the trap column. The analytes captured on the trap column are eluted by the gradient from aqueous to organic solvent onto the analytical column and to the MS (a). Total analysis from the trap column to the analytical column takes $15 \mathrm{~min}$. The sequence repeats until the entire dynamic in vitro biological experiment is completed 
a

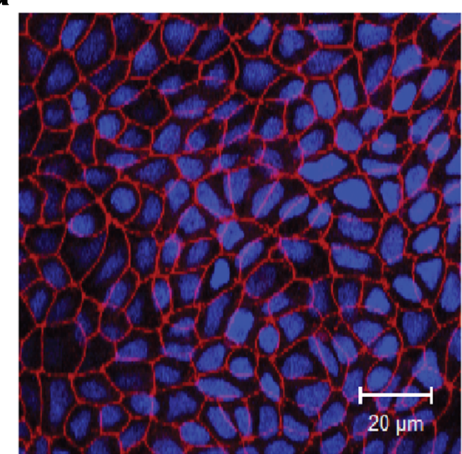

b

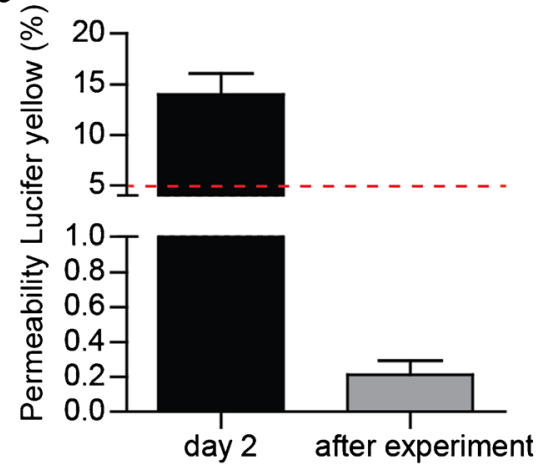

C

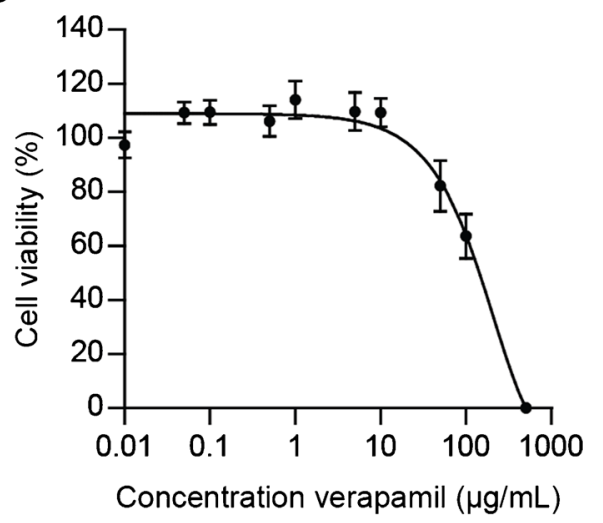

Fig. 3 (a) Confocal image of Caco-2/HT29-MTX cells cultured in a Transwell system for 21 days. Cells were stained for tight junction protein ZO-1/TJP1 (red) and cell nuclei (blue). (b) Permeability of Lucifer yellow across a monolayer of Caco-2/HT29-MTX cells after 2 days of culture and after permeability experiments (day 21), given as

\section{Results and discussion}

\section{Evidence-based bio-integrity of the intestinal barrier}

The human gastrointestinal tract is the second largest organ in the human body. It protects our body from pathogens and toxic compounds. On the other hand, it effectively absorbs nutrients from our food as well as orally administrated drugs. A reliable in vitro model should reflect this gatekeeper function. A prerequisite for in vitro permeability experiments is the formation of a leak-free monolayer of intestinal cells grown on a permeable membrane (i.e. Transwell). In our in vitro model, confocal imaging showed a network of tight junctions (Fig. 3a), demonstrating a tight monolayer of cells after 21 days of culture in the Transwell system. Furthermore, Lucifer yellow permeability testing following each compound permeability experiment indicated good barrier integrity of the monolayer, as Lucifer yellow is a marker for paracellular transport. Less than 5\% Lucifer yellow permeability is generally used as a cut-off value for a leaky monolayer [30], and an average permeability of $0.18 \% \pm 0.06 \%$ was experimentally obtained (Fig. 3b). To assess the flow-through Transwell model as a model for oral absorption, we examined its permeability characteristics using the model compound verapamil, of which extensive in vitro and in vivo permeability data can be found in the literature. Prior to the permeability experiments with verapamil, a non-toxic concentration of verapamil was determined to ensure proper cell viability during experiments. For this, we incubated non-differentiated cells for $24 \mathrm{~h}$ with increasing concentrations of verapamil to establish the desired non-toxic concentration for subsequent studies. These are worst-case conditions as in the permeability experiments, the exposure lasted $3 \mathrm{~h}$ and was executed on fully differentiated cells. The combination of a longer exposure time and the a percentage of the apical concentration $(\% \pm$ standard error of the mean (SEM)). (c) Cell viability of a Caco-2/HT29-MTX-E12 co-culture after the 24-h exposure to increasing concentrations of verapamil using the WST-1 mitochondrial activity assay. Viability is given as a percentage of the control ( $\% \pm \mathrm{SEM} ; n=3)$

use of proliferating cells results in a higher sensitivity towards cytotoxicity, compared to the shorter incubation and fully differentiated cells used in permeability experiments. The results showed that the cell viability of the co-culture of Caco-2 and HT29-MTX-E12 cells was $>80 \%$ after exposure to concentrations of verapamil at or below $10 \mu \mathrm{g} / \mathrm{mL}$ (Fig. 3c). Therefore, a concentration of $5 \mu \mathrm{g} / \mathrm{mL}$ was selected for permeability experiments in both the static and dynamic model systems.

\section{Online flow-through Transwell analysis system, design and performance}

Initial designs of the online total analysis system consisted of different configurations of switching valves (ESM Fig. S1), providing shorter run times and the possibility to select which effluent to measure. However, these configurations experienced severe analyte carryover between the two effluent streams, due to shared capillary tubing (carryover experiments described in the ESM). Finally, the in vitro model of the human intestinal epithelium could be successfully integrated with chip-based UPLC-QTOF-MS, using the set-up as shown in Fig. 2, thanks to the separate tubing and traps for apical and basolateral effluents, having high and low concentrations of analytes, respectively. A flow-through Transwell system (Fig. 1b) containing a co-culture of Caco-2 and HT29-MTX cells was operated upstream by a syringe pump equipped with a syringe heater to maintain a physiologically relevant temperature of the cell culture medium. HEPES was added to the cell culture medium as a $\mathrm{pH}$ buffer to maintain the physiologically relevant microenvironment. After starting the exposure for $15 \mathrm{~min}$, apical effluent was collected in the sample loop of the first switching valve (Fig. 2a). The sample was subsequently directed to a $\mathrm{C} 8$ trap column integrated on the 
third switching valve, allowing for analyte trapping and desalting (Fig. 2b). After trapping, the analyte was separated on a chip-based reversed-phase C18 column having an integrated nano-electrospray ionization emitter and analysed by QTOF-MS (Fig. 2c). The total analysis time including sample trapping, desalting and MS measurement was $15 \mathrm{~min}$. During the 15-min time period, the sample loop in the second switching valve was filled with the basolateral effluent for the next measurement (Fig. 2b, c) following the same trapping and desalting steps (Fig. 2d), but in a fully independent fluidic part of the set-up in order to exclude any carryover. Thus, every $15 \mathrm{~min}$, there was a switch between the apical and basolateral channels and this process was repeated until the end of the biological experiment. This final design turned out to be the best compromise with regard to lack of carryover, analysis time, frequency of sampling and analytical robustness. System stability was proven by introducing $5 \mu \mathrm{g} / \mathrm{mL}$ verapamil in HBSS for $3 \mathrm{~h}$ into the automated total analysis system by a syringe pump. During the complete run time of the experiment, the retention time for the verapamil peak was stable at $6.8 \mathrm{~min}$ (ESM Fig. S2a). Also, the pressure profile of the UPLC gradient pump attached to the third switching valve that runs over the trap columns and the analytical column confirmed no increase (column clogging) or decrease of pressure during the 3-h measurements (ESM Fig. S2b), thus demonstrating adequate removal of the very high level of salts in the medium.

\section{Temporal analysis of intestinal permeability}

\section{Verapamil}

Verapamil (ESM Fig. S3) was selected as a model compound as it is classified in category II of the Biopharmaceutics Classification System (BCS), meaning it is a highpermeability compound, and it is known to cross the intestinal epithelium predominantly via passive transcellular diffusion $[31,32]$. In order to assess the flow-through Transwell model as a model for oral absorption and to benchmark the automated online analysis system, three different set-ups were compared for verapamil permeability: (1) the traditional static Transwell system, (2) the dynamic flow-through Transwell system with offline sample collection and (3) the dynamic flow-through Transwell system with online analysis. For the static experiment, samples were collected on the basolateral side of the membrane at $t=0 \mathrm{~min}, 15 \mathrm{~min}, 30 \mathrm{~min}, 45 \mathrm{~min}$, $60 \mathrm{~min}, 120 \mathrm{~min}$ and $180 \mathrm{~min}$. In the dynamic offline system, samples were collected every 2 min using a fraction collector in a 96-well plate. The concentration of verapamil was determined by LC-MS/MS. Cumulative transport of verapamil across the intestinal layer in the static and dynamic offline system after $3 \mathrm{~h}$ was $13.5 \%$ and $12.7 \%$ of the exposure concentration, respectively, and followed a similar trend over time
(Fig. 4a, b). Variation among the biological samples in the dynamic system was somewhat larger, compared to the static system, but note that in this work, biological triplicate experiments were performed so all data points include both variations in cell culturing, in permeability and the analytical variation. The difference in variation in the dynamic system is probably due to some flow-induced shear stresses on the cells [33]. Having established that the permeability of verapamil is similar in a static and dynamic environment, thereby confirming a biologically functional in vitro intestinal barrier in the dynamic system, we used the verapamil permeability data from the dynamic offline system to benchmark the dynamic online analysis system. The cumulative transport data from the fully integrated online analysis system clearly demonstrates the accuracy and robustness of the automated system, as the results showed high similarity with the dynamic offline system, with a transport of $15.0 \%$ after $3 \mathrm{~h}$ of exposure (Fig. 4c). Additionally, the apparent permeability coefficients were calculated for all verapamil experiments, allowing comparison of our results against static in vitro permeability data found in the literature (Table 1). As shown in Table 1, the apparent permeability coefficients observed in our study corresponds with the range of data found in the literature. Comparison of our dynamic automated system with other dynamic systems is challenging as there is a high variety in designs and there are only a limited number of studies examining the absorptive capacity of the model $[10,14,20,40,41]$. For a widespread use of dynamic in vitro intestinal barrier models and incorporation of them in drug development trials and risk assessment approaches, more permeability data of model compounds needs to be generated using the dynamic devices, including benchmarking against the static Transwell and in vivo data.

\section{Ergotamin(in)e}

Apart from evaluating the permeability of the widely studied drug verapamil, we also examined the permeability of the epimers ergotamine and ergotaminine (ESM Fig. S4), from the ergot alkaloid family, across the intestinal barrier. Evaluating the oral bioavailability of ergot alkaloids is highly relevant as they can contaminate food and feed and little is known about their absorption characteristics or transport mechanisms [42]. Ergot alkaloids are found in plants infected with the fungus Claviceps purpurea. High oral intake of ergot alkaloids via contaminated food can result in ergotism also known as Saint Anthony's fire, with symptoms such as headaches, spasms and vasoconstriction [42]. Even though the inine form of ergot alkaloids is considered not biologically active [43], epimerization can occur under various conditions and could thus add to toxicity [44]. Just like for verapamil, we first established a non-toxic concentration for ergotamin(in)e as a mixture. As shown in Fig. S5 (ESM), the non-toxic 


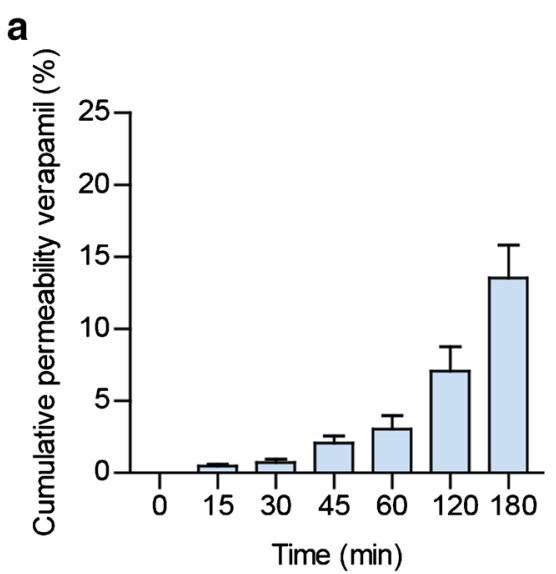

Fig. 4 (a) Permeability of verapamil across a monolayer of Caco-2/ HT29-MTX cells in a static Transwell system. Permeability is given as a percentage of the apical concentration $(\% \pm \mathrm{SEM} ; n=3)$. (b) Permeability of verapamil across a monolayer of Caco-2/HT29-MTX cells in the dynamic flow-through Transwell system. Permeability is

concentration for ergotamin(in)e was selected at $10 \mu \mathrm{g} / \mathrm{mL}$ and lower. Human studies have shown overall low oral bioavailability of ergotamine [45, 46], and it has been classified to be a BCS III compound, meaning a low-permeability compound [47]. Therefore, we used the highest non-toxic concentration possible for the ergotamin(in)e permeability experiments $(10 \mu \mathrm{g} / \mathrm{mL})$. The apparent permeability coefficient of ergotamine across the barrier of Caco- 2 and HT29-MTX cells in the static experiments was $8.6 \pm 1.2 \times 10^{-6} \mathrm{~cm} / \mathrm{s}$. Interestingly, the apparent permeability coefficient of the ergotaminine epimer was $50.2 \pm 5.8 \times 10^{-6} \mathrm{~cm} / \mathrm{s}$ (Fig. 5). Higher-permeability measurements of ergotaminine compared to ergotamine could be due to epimerization of ergotamine to ergotaminine; however, this is chemically rather

Table 1 Apparent permeability coefficient of verapamil described in the literature for different static in vitro model systems versus data obtained in this study

\begin{tabular}{lll}
\hline Cell model & $P_{\text {app }} \times 10^{-6} \mathrm{~cm} / \mathrm{s}$ & Ref. \\
\hline Caco-2 & $9.17-62.4$ & {$[34-37]$} \\
Caco-2 $^{(T C-7)}{ }^{\mathrm{a}}$ & $2.98 \pm 0.55$ & {$[38]$} \\
Caco-2/HT29-MTX $^{2}$ & $41.7 \pm 4.7$ & {$[39]$} \\
Caco-2/HT29-MTX/Raji B $^{\mathrm{b}}$ & $42.7 \pm 5.6$ & {$[39]$} \\
LLC-PK1 $^{\mathrm{c}}$ & $24 \pm 15.3$ & {$[34]$} \\
L-MDR1 $^{\text {c }}$ & $18.8 \pm 0.7$ & {$[34]$} \\
Caco-2/HT29-MTX (static) $_{\text {Caco-2/HT29-MTX (dynamic) }}$ & $20.9 \pm 3.9$ & This study \\
Caco-2/HT29-MTX (dynamic online) & $20.8 \pm 4.3$ & This study \\
\hline
\end{tabular}

${ }^{\mathrm{a}} \mathrm{TC}-7$ is a clone of the Caco- 2 cell line

${ }^{\mathrm{b}}$ Raji B is a human B lymphocyte cell line

${ }^{\mathrm{c}}$ LLC-PK1 cells are porcine epithelial cells, and L-MDR1 (multidrugresistant) cells are LLC-PK1 cells stably transfected with human MDR1 cDNA

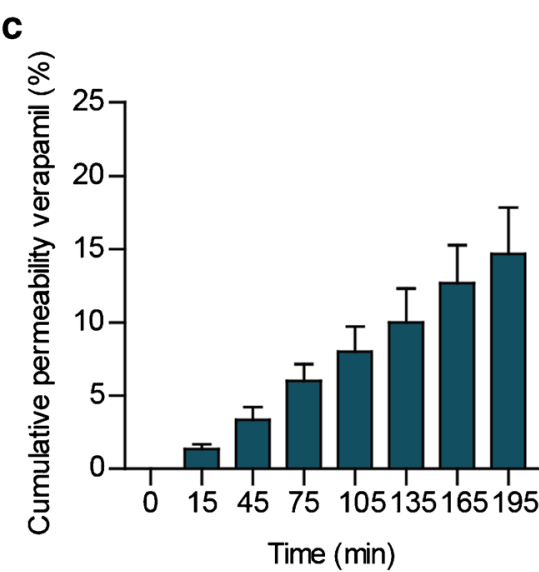

given as a calculated cumulative percentage of the apical concentration $(\% \pm \mathrm{SEM} ; n=3)$. (c) Permeability of verapamil across a monolayer of Caco-2/HT29-MTX cells in the dynamic flow-through Transwell system with online analysis. Permeability is given as a calculated cumulative percentage of the apical concentration $(\% \pm \mathrm{SEM} ; n=3)$

unlikely as the microenvironment conditions are kept stable during the 3-h experiments with no changes in $\mathrm{pH}$ or temperature. Another explanation could be that ergotamin(in)e is actively transported across the intestinal membrane and the transporter has a higher affinity for the -inine form. The opposite can also be true that an efflux transporter like Pglycoprotein (P-gp) has more affinity with ergotamine than with ergotaminine. Bromocriptine, another member of the ergot alkaloid family, is a known substrate for the efflux transporter P-gp [48]. For verapamil and ergotamine, we found similar permeability coefficients across the static and dynamic model systems, whereas for ergotaminine, permeability is 5 times lower in the dynamic experiments compared to the static experiments. Interestingly, in the dynamic experimental (both offline and online) measurements, the large difference between the epimer permeability rates is lost (Fig. 5). $P_{\text {app }}$ values for the ergotaminine epimer in the dynamic experiments are on the same level as for the ergotamine epimer. This difference clearly suggests that not the microenvironment as such but the cell layer is responsible for selective transport of the epimers and/or epimerization. Apparently, cell-induced epimerization

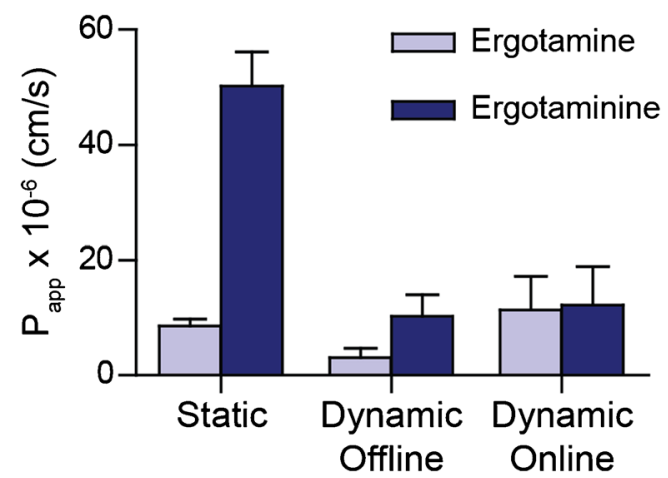

Fig. $5 P_{\text {app }}$ values of ergotamine and ergotaminine obtained in the static and dynamic (offline and online) systems ( \pm SEM, $n=3$ ) 
and/or active epimer selective transport is highly influenced by shear stress, highlighting the importance of dynamic systems for accurate representation of the microenvironment.

\section{Potential for online analysis of cell-induced product formation}

With the analysis of verapamil and ergotamin(in)e, we have demonstrated the robustness of the online analysis system to measure intestinal absorption in time. Besides temporal permeability analysis, the system could be suited for the detection of cell-induced product formation as well. For an initial feasibility experiment, we selected the compound granisetron (ESM Fig. S6), which is a serotonin 5$\mathrm{HT}_{3}$ receptor antagonist as a model substrate for metabolism in our intestinal barrier model. Granisetron is an oral drug that is used against nausea as a result of chemotherapy [49] and is metabolized by the enzymes CYP1A1 and CYP3A4, resulting in 7-hydroxygranisetron and 9desmethylgranisetron, respectively [50]. Caco-2 cells express the CYP1A1 enzyme, suggesting that granisetron might be metabolised in our Caco-2/HT29-MTX model [51]. Again first, a non-toxic concentration of $10 \mu \mathrm{g} / \mathrm{ml}$ granisetron was established (ESM Fig. S7). Next, an initial experiment was conducted using the newly developed dynamic online analysis system. After $3 \mathrm{~h}$ of exposure, $13.1 \%$ of granisetron translocated the in vitro intestinal barrier (Fig. 6a), but unfortunately, no cell-induced products were detected on the basolateral side of the cell barrier. Nevertheless, an additional ion with m/z 309 appeared on the apical side of the membrane (Fig. 6b). It was confirmed that the formation of this unknown compound was due to the presence of the cells, as the ion at $\mathrm{m} / \mathrm{z} 309$ was not detected after the 24-h incubation in the same matrix at

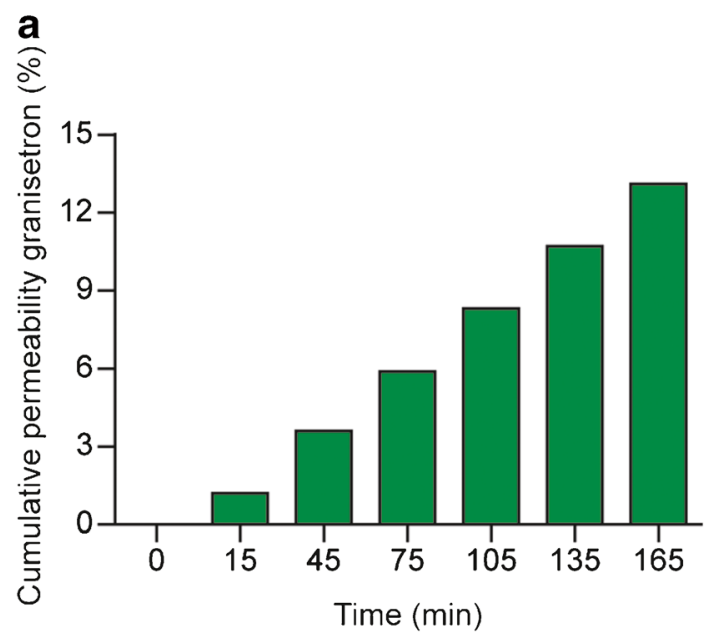

Fig. 6 (a) Permeability of granisetron across a monolayer of Caco-2/ HT29-MTX cells in the dynamic flow-through Transwell system with online analysis. Permeability is given as a calculated cumulative
$37{ }^{\circ} \mathrm{C}$ without cells (ESM Fig. S8). In other words, we can exclude chemical degradation as the cause of the product formation and, therefore, the formation of this unknown compound is due to the biologically active cells through either metabolism of granisetron or excretion of an unknown cell metabolite. However, more research is needed to elucidate the structure of this compound. Nevertheless, these results demonstrate the applicability and robustness of the automated online analysis system for measuring unknown product formation in the in vitro intestinal model.

\section{Conclusions}

Here, we developed an integrated online analysis system for the evaluation of intestinal absorption and unknown product formation by using a flow-through Transwell system and mass spectrometry, while ensuring full bio-integrity of the in vitro intestinal barrier. The biggest strength of the online analysis system is the combination of a functional dynamic biological model of the intestine with semi-continuous online analytical detection. The permeability of verapamil and ergotamin(in)e across a monolayer of Caco-2 and HT29-MTX cells was successfully studied in a time-resolved manner without any manual handling. Furthermore, we were able to detect unknown product formation upon exposing the intestinal cell layer to granisetron. While this work should be considered as a proof of concept, a wider range of different drugs, toxins or dietary compounds can be easily evaluated using this system. The system even allows for incorporation of other cell types in the flow-through Transwell system for more complex biological mechanistic-based studies. Last but not least, the system also allows future extensions with a dynamic in vitro oral

b

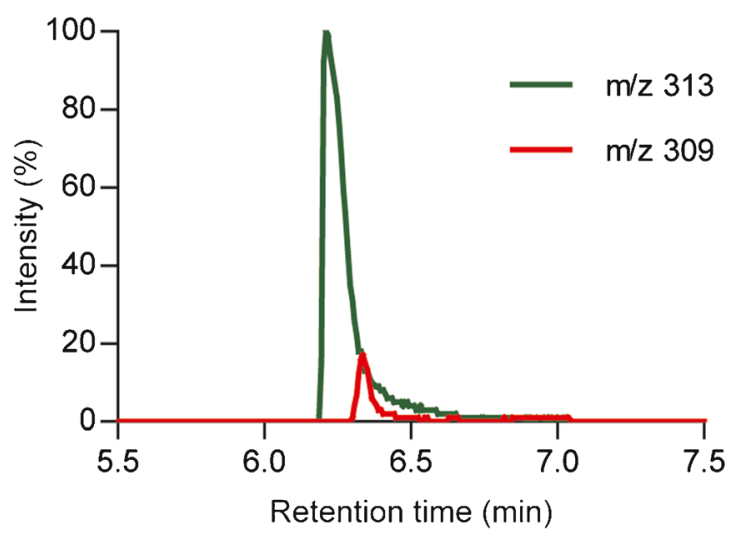

percentage of the apical concentration $(n=1)$. (b) reconstructed ion chromatogram of $\mathrm{m} / \mathrm{z} 313\left([\mathrm{M}+\mathrm{H}]^{+}\right.$) and 309 (unknown) at the time point of $30 \mathrm{~min}$ on the apical side 
digestion system or a liver compartment in order to provide a full oral bioavailability system with semi-continuous readout of absorption and biotransformation.

Acknowledgements We thank Patrick Mulder and Elena de Vries from Wageningen Food Safety Research for their assistance with the LC-MS/ MS analysis of ergotamin(in)e.

Funding information This research received funding from the Dutch Research Council (NWO) in the framework of the Technology Area PTA-COAST3 (project no. 053.21.116) of the Fund New Chemical Innovations with Wageningen University, University of Groningen, Wageningen Food Safety Research, FrieslandCampina, Micronit Microtechnologies, Galapagos and EuroProxima as partners.

\section{Compliance with ethical standards}

Conflict of interest The authors declare that they have no conflicts of interest.

Open Access This article is licensed under a Creative Commons Attribution 4.0 International License, which permits use, sharing, adaptation, distribution and reproduction in any medium or format, as long as you give appropriate credit to the original author(s) and the source, provide a link to the Creative Commons licence, and indicate if changes were made. The images or other third party material in this article are included in the article's Creative Commons licence, unless indicated otherwise in a credit line to the material. If material is not included in the article's Creative Commons licence and your intended use is not permitted by statutory regulation or exceeds the permitted use, you will need to obtain permission directly from the copyright holder. To view a copy of this licence, visit http://creativecommons.org/licenses/by/4.0/.

\section{References}

1. Dosh RH, Jordan-Mahy N, Sammon C, Le Maitre CL. Tissue engineering laboratory models of the small intestine. Tissue Eng Part B-Re. 2018;24(2):98-111.

2. Artursson P, Palm K, Luthman K. Caco-2 monolayers in experimental and theoretical predictions of drug transport. Adv Drug Deliv Rev. 2001;46(1-3):27-43.

3. Behrens I, Stenberg P, Artursson P, Kissel T. Transport of lipophilic drug molecules in a new mucus-secreting cell culture model based on HT29-MTX cells. Pharm Res. 2001;18(8):1138-45.

4. Pan F, Han L, Zhang Y, Yu Y, Liu J. Optimization of Caco-2 and HT29 co-culture in vitro cell models for permeability studies. Int J Food Sci Nutr. 2015;66(6):680-5.

5. Billat PA, Roger E, Faure S, Lagarce F. Models for drug absorption from the small intestine: where are we and where are we going? Drug Discov Today. 2017;22(5):761-75.

6. Ergir E, Bachmann B, Redl H, Forte G, Ertl P. Small force, big impact: next generation organ-on-a-chip systems incorporating biomechanical cues. Front Physiol. 2018;9:1417.

7. Sosa-Hernandez JE, Villalba-Rodriguez AM, Romero-Castillo KD, Aguilar-Aguila-Isaias MA, Garcia-Reyes IE, Hernandez-Antonio A, et al. Organs-on-a-chip module: a review from the development and applications perspective. Micromachines-Basel. 2018;9(10): 536.
8. Rothbauer M, Rosser JM, Zirath H, Ertl P. Tomorrow today: organon-a-chip advances towards clinically relevant pharmaceutical and medical in vitro models. Curr Opin Biotechnol. 2019;55:81-6.

9. Esch MB, Mahler GJ, Stokol T, Shuler ML. Body-on-a-chip simulation with gastrointestinal tract and liver tissues suggests that ingested nanoparticles have the potential to cause liver injury. Lab Chip. 2014;14(16):3081-92.

10. Pocock K, Delon L, Bala V, Rao S, Priest C, Prestidge C, et al. Intestine-on-a-chip microfluidic model for efficient in vitro screening of oral chemotherapeutic uptake. Acs Biomater Sci Eng. 2017;3(6):951-9.

11. Ramadan Q, Jafarpoorchekab H, Huang CB, Silacci P, Carrara S, Koklü G, et al. NutriChip: nutrition analysis meets microfluidics. Lab Chip. 2013;13(2):196-203.

12. Shim KY, Lee D, Han J, Nguyen NT, Park S, Sung JH. Microfluidic gut-on-a-chip with three-dimensional villi structure. Biomed Microdevices. 2017;19(2):37.

13. Kim HJ, Huh D, Hamilton G, Ingber DE. Human gut-on-a-chip inhabited by microbial flora that experiences intestinal peristalsislike motions and flow. Lab Chip. 2012;12(12):2165-74.

14. Imura Y, Asano Y, Sato K, Yoshimura E. A microfluidic system to evaluate intestinal absorption. Anal Sci. 2009;25(12):1403-7.

15. Kasendra M, Tovaglieri A, Sontheimer-Phelps A, JaliliFiroozinezhad S, Bein A, Chalkiadaki A, et al. Development of a primary human small intestine-on-a-chip using biopsy-derived organoids. Sci Rep-Uk. 2018;8(1):2871.

16. Tan HY, Trier S, Rahbek UL, Dufva M, Kutter JP, Andresen TL. A multi-chamber microfluidic intestinal barrier model using Caco-2 cells for drug transport studies. PLoS One. 2018;13(5):e0197101.

17. Trietsch SJ, Naumovska E, Kurek D, Setyawati MC, Vormann MK, Wilschut KJ, et al. Membrane-free culture and real-time barrier integrity assessment of perfused intestinal epithelium tubes. Nat Commun. 2017;8(1):262.

18. Santbergen MJC, van der Zande M, Bouwmeester H, Nielen MWF. Online and in situ analysis of organs-on-a-chip. Trac-Trend Anal Chem. 2019;115:138-46.

19. Gao D, Li H, Wang N, Lin JM. Evaluation of the absorption of methotrexate on cells and its cytotoxicity assay by using an integrated microfluidic device coupled to a mass spectrometer. Anal Chem. 2012;84(21):9230-7.

20. Gao D, Liu H, Lin JM, Wang Y, Jiang Y. Characterization of drug permeability in Caco-2 monolayers by mass spectrometry on a membrane-based microfluidic device. Lab Chip. 2013;13(5):97885.

21. Wei H, Li H, Gao D, Lin JM. Multi-channel microfluidic devices combined with electrospray ionization quadrupole time-of-flight mass spectrometry applied to the monitoring of glutamate release from neuronal cells. Analyst. 2010;135(8):2043-50.

22. Mao S, Zhang J, Li H, Lin JM. Strategy for signaling molecule detection by using an integrated microfluidic device coupled with mass spectrometry to study cell-to-cell communication. Anal Chem. 2013;85(2):868-76.

23. Wei H, Li H, Mao S, Lin JM. Cell signaling analysis by mass spectrometry under coculture conditions on an integrated microfluidic device. Anal Chem. 2011;83(24):9306-13.

24. Dugan CE, Grinias JP, Parlee SD, El-Azzouny M, Evans CR, Kennedy RT. Monitoring cell secretions on microfluidic chips using solid-phase extraction with mass spectrometry. Anal Bioanal Chem. 2017;409(1):169-78.

25. Marasco CC, Enders JR, Seale KT, McLean JA, Wikswo JP. Realtime cellular exometabolome analysis with a microfluidic-mass spectrometry platform. PLoS One. 2015;10(2):e0117685.

26. Abdelkhaliq A, van der Zande M, Undas AK, Peters RJB, Bouwmeester $\mathrm{H}$. Impact of in vitro digestion on gastrointestinal fate and uptake of silver nanoparticles with different surface modifications. Nanotoxicol. 2019:1-16. 
27. Hubatsch I, Ragnarsson EGE, Artursson P. Determination of drug permeability and prediction of drug absorption in Caco-2 monolayers. Nat Protoc. 2007;2(9):2111-9.

28. Giusti S, Sbrana T, La Marca M, Di Patria V, Martinucci V, Tirella A, et al. A novel dual-flow bioreactor simulates increased fluorescein permeability in epithelial tissue barriers. Biotechnol J. 2014;9(9):1175-84.

29. Yeon JH, Park JK. Drug permeability assay using microholetrapped cells in a microfluidic device. Anal Chem. 2009;81(5): 1944-51.

30. Hidalgo IJ, Raub TJ, Borchardt RT. Characterization of the humancolon carcinoma cell-line (Caco-2) as a model system for intestinal epithelial permeability. Gastroenterology. 1989;96(3):736-49.

31. Engman H, Tannergren C, Artursson P, Lennernas H. Enantioselective transport and CYP3A4-mediated metabolism of R/S-verapamil in Caco-2 cell monolayers. Eur J Pharm Sci. 2003;19(1):57-65.

32. Tubic-Grozdanis M, Bolger MB, Langguth P. Application of gastrointestinal simulation for extensions for biowaivers of highly permeable compounds. AAPS J. 2008;10(1):213-26.

33. Gayer CP, Basson MD. The effects of mechanical forces on intestinal physiology and pathology. Cell Signal. 2009;21(8):1237-44.

34. Pauli-Magnus C, von Richter O, Burk O, Ziegler A, Mettang T, Eichelbaum M, et al. Characterization of the major metabolites of verapamil as substrates and inhibitors of P-glycoprotein. J Pharmacol Exp Ther. 2000;293(2):376-82.

35. Westerhout J, de Steeg EV, Grossouw D, Zeijdner EE, Krul CAM, Verwei M, et al. A new approach to predict human intestinal absorption using porcine intestinal tissue and biorelevant matrices. Eur J Pharm Sci. 2014;63:167-77.

36. Faasen F, Vogel G, Spanings H, Vromans H. Caco-2 permeability, P-glycoprotein transport ratios and brain penetration of heterocyclic drugs. Int J Pharm. 2003;263(1-2):113-22.

37. Fossati L, Dechaume R, Hardillier E, Chevillon D, Prevost C, Bolze $\mathrm{S}$, et al. Use of simulated intestinal fluid for Caco-2 permeability assay of lipophilic drugs. Int J Pharm. 2008;360(1-2):148-55.

38. Turco L, Catone T, Caloni F, Di Consiglio E, Testai E, Stammati A. Caco-2/TC7 cell line characterization for intestinal absorption: how reliable is this in vitro model for the prediction of the oral dose fraction absorbed in human? Toxicol in Vitro. 2011;25(1):13-20.

39. Lozoya-Agullo I, Araújo F, González-Álvarez I, Merino-Sanjuán M, González-Álvarez M, Bermejo M, et al. Usefulness of Caco-2/ HT29-MTX and Caco-2/HT29-MTX/Raji B coculture models to predict intestinal and colonic permeability compared to Caco-2 monoculture. Mol Pharm. 2017;14(4):1264-70.
40. Kulthong K, Duivenvoorde L, Mizera BZ, Rijkers D, ten Dam G, Oegema $\mathrm{G}$, et al. Implementation of a dynamic intestinal gut-on-achip barrier model for transport studies of lipophilic dioxin congeners. RSC Adv. 2018;8(57):32440-53.

41. Kimura H, Yamamoto T, Sakai H, Sakai Y, Fujii T. An integrated microfluidic system for long-term perfusion culture and on-line monitoring of intestinal tissue models. Lab Chip. 2008;8(5):741-6.

42. EFSA. Scientific opinion on ergot alkaloids in food and feed. EFSA J. 2012;10(7):2798.

43. Klotz JL. Activities and effects of ergot alkaloids on livestock physiology and production. Toxins (Basel). 2015;7(8):2801-21.

44. Hafner M, Sulyok M, Schuhmacher R, Crews C, Krska R. Stability and epimerisation behaviour of ergot alkaloids in various solvents. World Mycotoxin J. 2008;1(1):67-78.

45. Little PJ, Jennings GL, Skews H, Bobik A. Bioavailability of dihydroergotamine in man. Br J Clin Pharmacol. 1982;13(6):785-90.

46. Sanders SW, Haering N, Mosberg H, Jaeger H. Pharmacokinetics of ergotamine in healthy volunteers following oral and rectal dosing. Eur J Clin Pharmacol. 1986;30(3):331-4.

47. Sun L, Liu X, Xiang R, Wu C, Wang Y, Sun Y, et al. Structurebased prediction of human intestinal membrane permeability for rapid in silico BCS classification. Biopharm Drug Dispos. 2013;34(6):321-35.

48. Vautier S, Lacomblez L, Chacun H, Picard V, Gimenez F, Farinotti $\mathrm{R}$, et al. Interactions between the dopamine agonist, bromocriptine and the efflux protein, P-glycoprotein at the blood-brain barrier in the mouse. Eur J Pharm Sci. 2006;27(2-3):167-74.

49. Plosker GL, Goa KL. Granisetron - a review of its pharmacological properties and therapeutic use as an antiemetic. Drugs. 1991;42(5): 805-24.

50. Boppana VK, Miller-Stein C, Schaefer WH. Direct plasma liquid chromatographic-tandem mass spectrometric analysis of granisetron and its 7-hydroxy metabolite utilizing internal surface reversed-phase guard columns and automated column switching devices. J Chromatogr B. 1996;678(2):227-36.

51. Sergentengelen T, Delistrie V, Schneider YJ. Phase-I and phase-II biotransformations in living Caco 2 cells cultivated under serumfree conditions - selective apical excretion of reaction-products. Biochem Pharmacol. 1993;46(8):1393-401.

Publisher's note Springer Nature remains neutral with regard to jurisdictional claims in published maps and institutional affiliations. 